\title{
Predictive Model of ACC Speed to Enhance Engine Operating Conditions
}

\author{
Srikanth Kolachalama, Hafiz Malik \\ Electrical and Computer Engineering, University of Michigan, Dearborn 48128, USA
}

\begin{abstract}
The ACC feature when activated augments the engine performance in real-time. This article presents a novel methodology to predict the optimal adaptive cruise control set speed profile (ACCSSP) by considering all the effecting parameters. This paper investigates engine operating conditions (EOC) criteria to develop a predictive model of ACCSSP in real-time. We developed a deep learning (DL) model using the NARX method to predict engine operating point (EOP) mapping the vehicle-level vectors (VLV). We used real-world field data obtained from Cadillac test vehicles driven by activating the ACC feature for developing the DL model. We used a realistic set of assumptions to estimate the VLV for the future time steps for the range of allowable speed values and applied them at the input of the developed DL model to generate multiple sets of EOP's. We imposed the defined EOC criteria on these EOPs, and the top three modes of speeds satisfying all the requirements are derived for each second. Thus, three eligible speed values are estimated for each second, and an additional criterion is defined to generate a unique ACCSSP for future time steps. Performance comparison between predicted and constant ACCSSPs indicates that the predictive model outperforms constant ACCSSP.
\end{abstract}

KEYWORDS: Adaptive Cruise Control, Driver behaviour, Deep learning, Engine Operating Point Corresponding author. e-mail: skola@umich.edu; Co author. e-mail: hafiz@umich.edu;

\section{INTRODUCTION}

The introduction of automobiles into the world inculcated innovation in many aspects of engineering, including design and manufacturing (Townsend and Calantone, 2014) [1]. Engineers worldwide continuously strive to develop cutting-edge technologies to augment the riders' comfort, traffic behaviour, enhance safety and fuel economy (Katzenbach, 2015) [2]. Among the many features integrated into the vehicle, the ACC system developed by reference (Labuhn and Chundrlik, 1995) played a vital role, affecting safety and EOC [3]. The intricate concept of an ACC system is to produce controlled acceleration without disengaging the cruise in the user-defined proximity and strictly follow the user command of set speed (Marsden et.al, 2001) [4]. Also, we could conclude from the existing literature (Mahdinia et.al, 2020) that activation of ACC results in lower IFCR [5]. Therefore, activating the ACC feature for traversing long trips would augment EOC.

However, identifying the optimal ACCSSP by considering the dynamic state of the vehicle for a definite coordinate on the terrain is an unsolved, challenging task for engineers. Researchers have performed the parametric optimisation of ACC output in the existing literature by analysing the realtime data of driver behaviour, traffic congestion, terrain data, and environmental factors. (Stanton et.al, 2005, Hoedemaeker et.al, 1998, Kesting et.al, 2007, RudinBrown et.al, 2004, Moon et.al, 2008, Rosenfeld et.al, 2015) considered driver behaviour as the key input to develop the control algorithm using analytical techniques and to tune the outputs of the ACC system [6-11]. The enhancements of vehicle connectivity opened doors to obtain real-time traffic congestion information. (Milanés et.al, 2013:2014, Kesting et.al, 2008:2007, Ploeg et.al, 2011) adopted the DL models to estimate the ACCSSP and desired acceleration based on the traffic congestion data retrieved in real-time [12-15]. (Li et.al, 2017, Lu et.al, 2019, Vedam, 2015, Kolmanovsky and Filev, 2010, Gáspár and Németh, 2014:2011:2013, Ma et.al, 2019) adopted the terrain data to estimate the ACC control parameters to reduce IFCR using the known mathematical models [16-23].

Existing techniques rely on either one or two affecting factors as inputs to predict ACCSSP considered, but none of the researchers included all the factors in conjunction to the best of our knowledge. Recently we have developed a DL model mapping all the VLV and EOP (Kolachalama et.al, 2021) [24]. This DL model produced the best results for the ACC activated test case and included all the factors mentioned above, excluding traffic congestion information. This paper applied predefined EOC criteria to the predicted EOP, and the optimal ACCSSP is estimated corresponding to augmented EOC. We validated the proposed model using the real-time test vehicle data-driven road segments that included arterial, state ways, and freeways. The below sections show the detailed procedure adopted.

The rest of the article is organised as follows: Section 2 and 4 propose predicting EOP and ACCSSP, whereas Section 3 defines the EOC criteria applied to the EOP to estimate ACCSSP. In Section 5, the detailed results of the predictive model and experimental techniques are presented. 


\section{PREDICTIVE MODEL for EOP}

We adopted the commonly available DL methods, NARX and LSTM, to develop predictive models involving timesensitive data (Diaconescu, 2008) [25]. (Kolachalama et.al, 2021), compared NARX and LSTM methods using the real-time test case (2019 Cadillac XT6) and proved that the NARX method outperforms the LSTM model [24]. Hence, in this research, a similar NARX DL model is used with default training options to predict EOP as shown in Table 4.

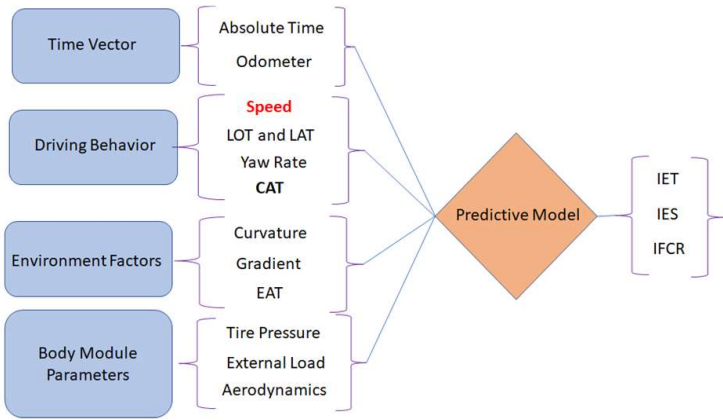

Figure 1. Predictive model — Inputs and Outputs [5]

As mentioned in the previous section, Figure 1 depicts the DL model to predict the EOP mapping VLV. The outputs of the DL model consist of the elements IET, IES, and IFCR, and the VLV, which embed with driver behavior, body module parameters, environmental factors, and terrain data. The DBV consists of three elements speeding [Speed, LOT], steering [YAR, LAT] and CAT (Kolachalama et.al, 2021) [24][26]. The parameters odometer, tire pressure, curvature, and gradient affect the vehicle traction, whereas CAT and EAT influence thermal stress on the engine (Kolachalama et.al, 2008) [27]. Also, there is no loss of generality in replacing the gradient with the vehicle posture's Euler angles, which affect the traction under no-slip (Eathakota et.al, 2010) [28-29].

\section{Metric for Optimal EOC}

In this section, we defined the metrics for EOC criteria, which reflect optimal EOP.

\subsection{Generic Criteria}

The predicted EOP for the vehicles traversing the speeds ranging [25 45] MPH (arterial roads) have closer proximity to the ideal EOP. In this scenario, the IET has a higher magnitude; on the contrary, for the speeds ranging [65 85], MPH (freeways) have higher IES recorded.
Also, the allowable speeds for the state ways range between [45 65] MPH are considered the green zone with maximum fuel economy (low IFCR). Hence, the generic criteria for augmented EOC would include higher IET, higher IES, and lower IFCR, along with the maximum distance traversed for the trip.

\subsection{Euclidean Distance-Ideal EOP}

An engine map calibrated at the manufacturing plant for every model by all automotive OEMs represents the engine's performance. In general, the ideal EOP for any vehicle represents the coordinate (centroid) on the map with the lowest IFCR. An example of the engine map for the vehicle 2014 Chevrolet 4.3L EcoTec3 LV3 Engine is shown in Figure 2. The ideal EOP for this vehicle was estimated to be the coordinate [285 Nm, $2250 \mathrm{RPM}, 225 \mathrm{~g} / \mathrm{kwhr}$. Similarly, the ideal EOPs for the three test vehicles are empirically estimated, as shown in section A: Table 6.

Hence, we defined the line segment conjoining the predicted and ideal EOP as the EOC vector, represented in Figure 2. The magnitude of the EOC vector represents the $E D_{i}$ shown in Equation 1. In the 2D plane, there is no loss of generality in ignoring the parameter IES, as it is proportional to the vehicle speed. Therefore, lower ED represents increased EOC.

$$
E D_{i}=\sqrt{\left(I E T_{i}-I E T_{k}\right)^{2}+\left(I F C R_{i}-I F C R_{k}\right)^{2}}
$$

\subsection{Engine Caliber-Speed and Torque}

The engine's capability is measured by two standard parameters [ESC, ETC]. These parameters are the ratios that define the torque produced per unit of fuel consumption and the speed produced per unit of torque. Higher ETC and ESC are the desired criteria for every vehicle's

trip.

$$
\mathrm{ETC}=\frac{I E T}{I F C R}(2) \quad \mathrm{ESC}=\frac{I E S}{I E T}
$$

3.4. Smoothness measure-EOC parameters

The combustion of fuel in the engine produces torque with fluctuating magnitudes. However, all the elements of EOP should have smooth behavior (Tanaka et.al, 1987, Li et.al, 2017) [30] [31]. Hence, as an additional optimal EOC metric we defined the smoothness measure for all the six parameters-IET, IES, IFCR, ED, ESC, and ETC. We used the spline to fit the data points of EOC parameters by normalizing the data. The optimal fit criteria were measured by traditional statistical techniques R/Adjusted square, RMSE, and SSE, using the built-in toolboxes of MATLAB as shown in section B: Table 6. 


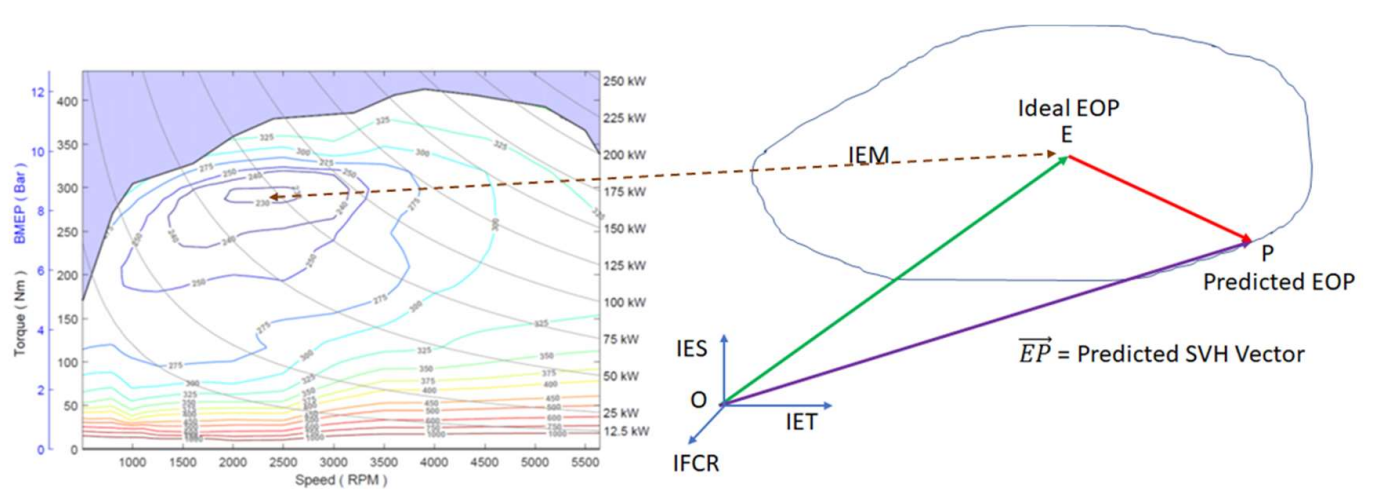

Figure 2. Engine Map-EOC Vector

Environmental Protection Agency, National Vehicle and Fuel Emissions Laboratory, National Center for Advanced Technology, Ann Arbor, Michigan, USA. Version 2018-08

\section{PREDICTION of ACCSSP}

The prediction of ACCSSP was categorised into four steps, as described in the following sections.

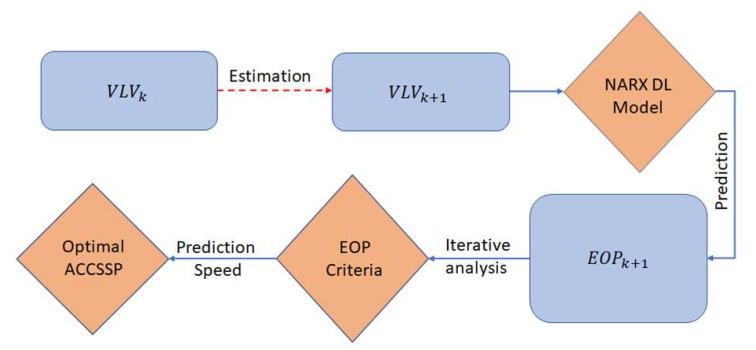

Figure 3. Process - Prediction of ACCSSP

4.1. Estimation of future input states-DL Model Step 1: Relative to the current state of the vehicle $\left(V L V_{k}\right)$, the future input values $\left(V L V_{k+1}\right)$ of the DL model (Figure $10)$ are estimated using the relations shown in Table 7 . The parameter odometer $\left(O_{k+1}\right)$ was calculated using the speed $\left(S_{k}\right)$ with the constant time step by basic linear interpolation. The LOT $\left(L_{o(k+1)}\right)$ is estimated based on the vehicle resistance shown in the equation set in Table 7 , and the parameters YAR $\left(Y_{a(k+1)}\right)$ and $\operatorname{LAT}\left(L_{a(k+1)}\right)$ are calculated assuming ISB (Kolachalama et.al, 2018) [25]. The environmental parameters $E A T_{k+1}$, terrain data, $\left[R R C_{k+1}, \theta_{g(k)}\right]$, are retrieved using the GPS location and the infotainment maps. The magnitudes of the tire pressure $\left(T P_{k+1}\right)$ and $C A T_{k+1}$ are assumed to be equal to the previous time step. (Table 8).

\subsection{Prediction of outputs-DL Model}

Step 2: We estimated the input sets for future time steps (1 second - $\left[\begin{array}{ll}T_{0} & T_{1}\end{array}\right]$ ) for the AVS range (e.g., [SL-10, SL]). Thus, we generated eleven sets of inputs, and fed them into the DL model, and predicted a corresponding eleven sets of outputs (EOP's). (Table 9)

4.3. Estimation of ACC Speed values-EOC Criteria. Step 3: We applied the EOC criteria defined in section III for the eleven predicted EOP's (Table 9). The top six performing speed values are selected for each EOC parameter, and hence, the top three modes of speeds (EVS) are calculated for each time step (Table 10). We incorporated a similar procedure for the next ten seconds, and ACC Matrix (3X10) was developed (Table 11).

\subsection{Algorithm to predict ACCSSP}

Step 4: Every second has three EVS, resulting in a maximum of $3^{10}$ possible ACCSSP's for 10 seconds. The following conditions are defined to identify a unique ACCSSP inspired by the Dubin path traverse problem (La Valle, 2011) [32].

1. Assuming the ACCSSP at $T_{k}$ is $S_{k}$, if the EVS is either $S_{k}+1, S_{k}$, or $S_{k}-1$, then the highest magnitude among the three is selected as $S_{k+1}$.

2. $S_{1}$ is chosen closer to $S_{0}$ (IAS). If this results in two values, then the higher value is considered as $S_{1}$.

3. If the eligible speeds at $T_{k+1}$ are neither $S_{k}+1, S_{k}$, nor $S_{k}$ 1 , then $S_{k+1}=S_{k}$.

4. If $S_{k+1}=S_{k}$ for more than 10 seconds, then $S_{k+1}=S_{k}+1$ if $S_{k}+1 \leq \mathrm{SL}$ or $S_{k}-1$ if $S_{k}=\mathrm{SL}$.

\section{EXPERIMENTAL RESULTS}


Author

A series of experiments are designed, analysed and evaluated on a real-time dataset to evaluate the performance of the proposed framework.

\subsection{Dataset retrieval.}

We conducted this research using three test vehicles, a 2019 Cadillac XT6, a 2020 Cadillac CT5, and a 2021 Cadillac CT4, obtained from GMC. A two-step procedure was employed to retrieve the data from the vehicle CAN bus (Li et.al, 2008) [33]. We connected the hardware neoVI to the vehicle and retrieved the data retrieval using the software Vehicle Spy. This tool records data in realtime (Gallardo, 2018) and allows the user to selectively retrieve the signal data required for analysis [34]. We performed the real-time test procedure by activating the ACC feature, and approximately 1E5 time-step snippet of data was collected for each vehicle at a frequency of $10 \mathrm{~Hz}$, assuming a no-slip (Eathakota et.al, 2008) [28-29].

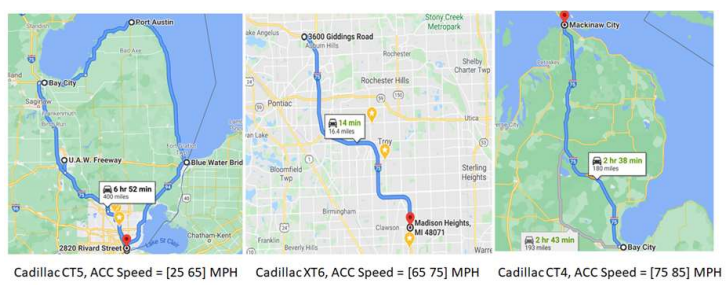

Figure 4. Path traversed-Test vehicles [Google Maps]

The test cases are developed by driving the vehicles on selected road segments covering all the arterial, state ways, and freeways scenarios. Shown in Figure 4 are the paths traversed by the Cadillac test vehicles. The properties of the six datasets used for this analysis, including the input and output parameters of the DL model, are shown in Tables 1-3. Please find the details of the predictive model in the following sections.

\subsection{Prediction of EOP}

The properties of the NARX model and the test cases used for training are shown in Table 4. We developed individual training networks using the DL toolbox of MATLAB for the three vehicles' test data and the predicted EOPs, as shown in Figures 5-10. Each figure consists of three parts: IET (left), IES (middle), and IFCR (right). Furthermore, each plot compares the measured data (blue) with the predicted values (orange). We validated the performance of the NARX DL model prediction using traditional statistical techniques (RMSE, FOD, SNR) to compare the actual and predicted values of EOP, as reported in Table 5. We conclude that IES follows a smooth curve from Figures 5-10, whereas IFCR and IET oscillate.

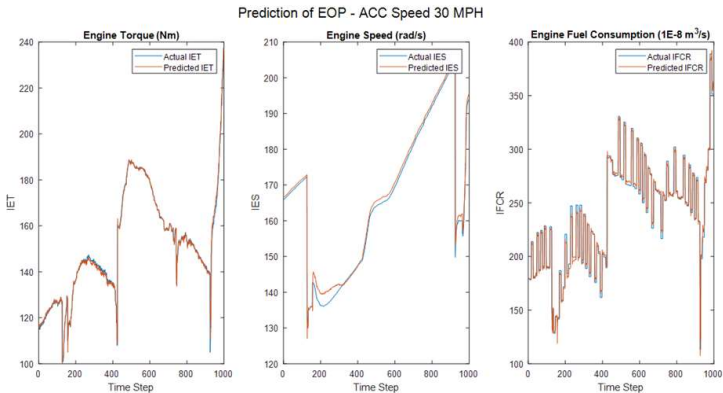

Figure 5. ACCSSP $=30 \mathrm{MPH}, 2020$ Cadillac CT5

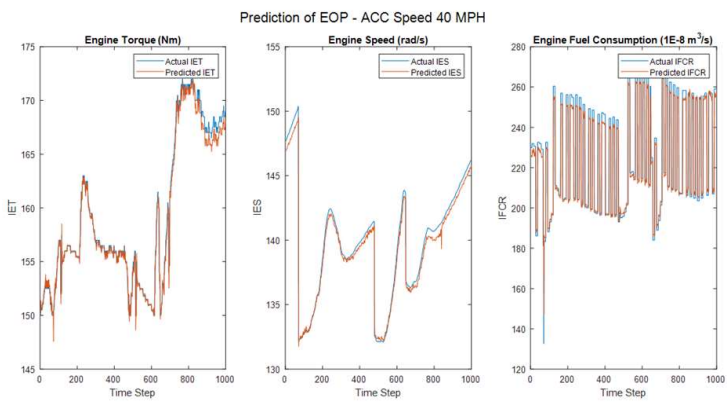

Figure 6. ACCSSP $=40 \mathrm{MPH}, 2020$ Cadillac CT5

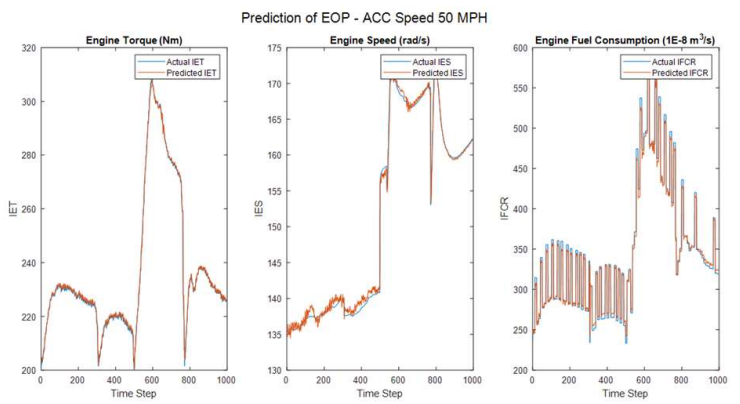

Figure 7. ACCSSP $=50 \mathrm{MPH}, 2020$ Cadillac CT5

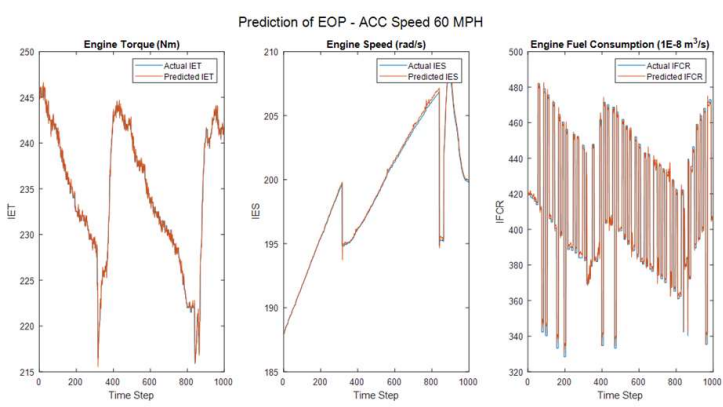

Figure 8. ACCSSP $=60 \mathrm{MPH}, 2020$ Cadillac CT5 
Author
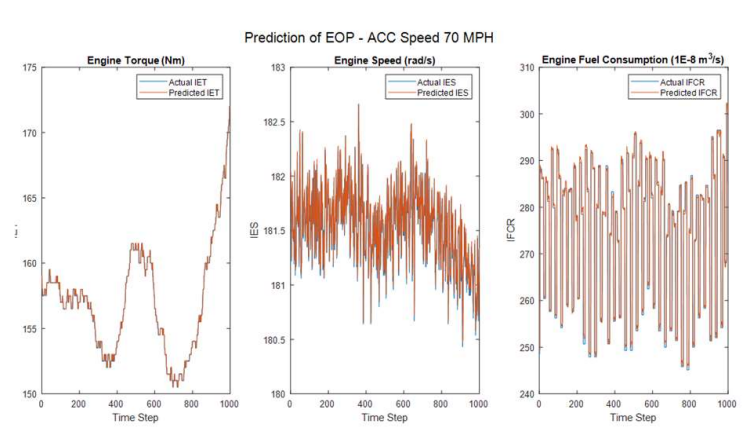

Figure 9. ACCSSP $=70$ MPH, 2019 Cadillac XT6

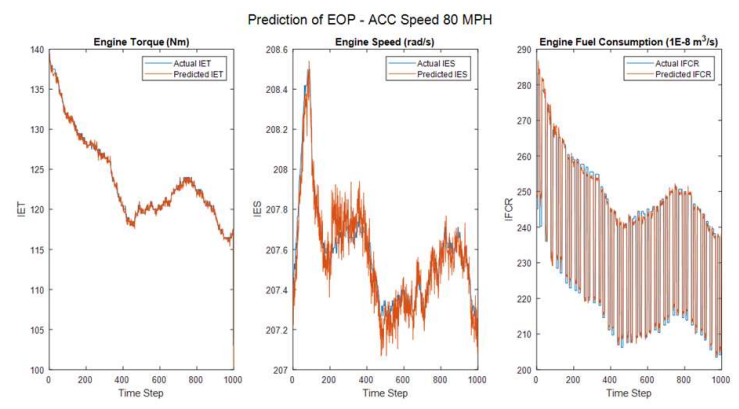

Figure 10. ACCSSP $=80 \mathrm{MPH}, 2021$ Cadillac CT4

\subsection{Estimation of Optimal ACCSSP}

The developed DL model and the steps defined in Section 4 are used to estimate the optimal ACCSSP for each test case. An example, for the test case of the vehicle 2019 Cadillac XT6, is selected with the AVS $=[65$ 75] MPH, and the corresponding results are shown in Tables $8-10$. The IAS $\left(S_{0}\right)$ is varied in the range [65 75] MPH for the ACC Matrix (Table 11), and Step 4 is applied to the EVS, which results in eight ACCSSP's shown in Figure 11. Thus for $S_{0}=70 \mathrm{MPH}$, the predicted ACCSSP is the row vector $([71,71,71,71,72,72,73,73,74,74] \mathrm{MPH})$ plotted in Figure

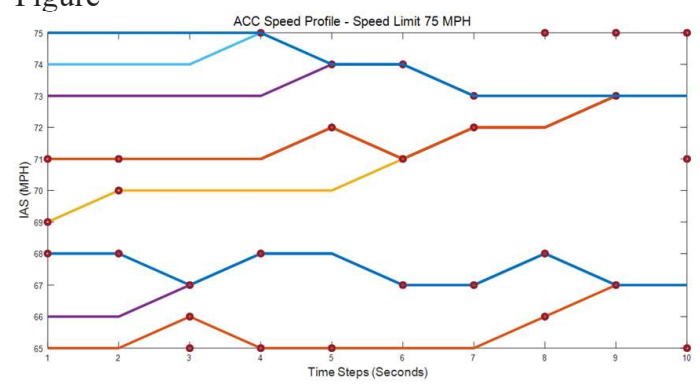

Figure 11. ACCSSP, IAS $=[6575] \mathrm{MPH}, \mathrm{SL}=75 \mathrm{MPH}$

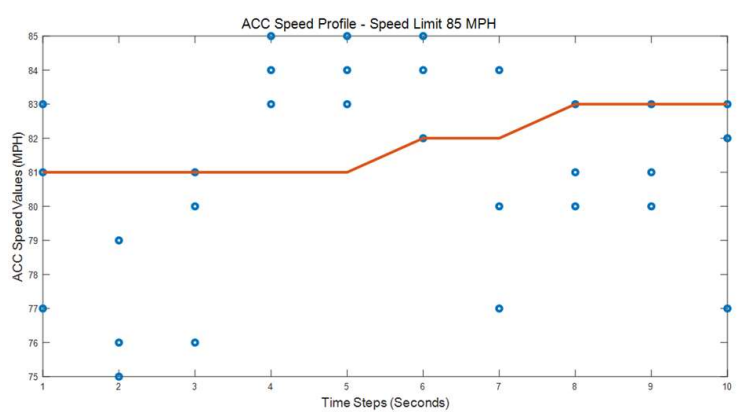

Figure 12. ACCSSP, IAS $=80 \mathrm{MPH}, \mathrm{SL}=85 \mathrm{MPH}$

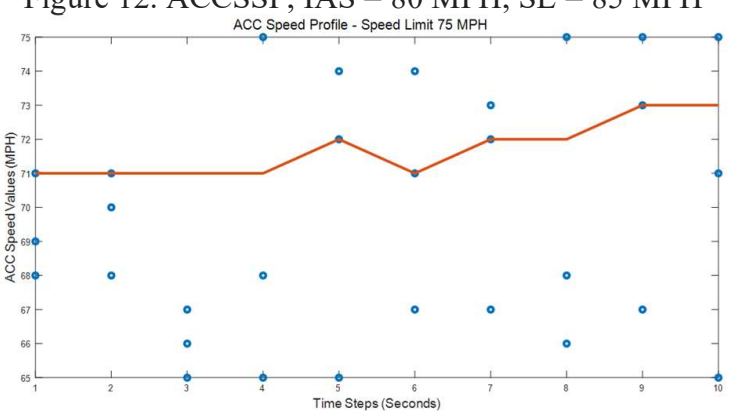

Figure 13. ACCSSP, IAS $=70 \mathrm{MPH}, \mathrm{SL}=75 \mathrm{MPH}$

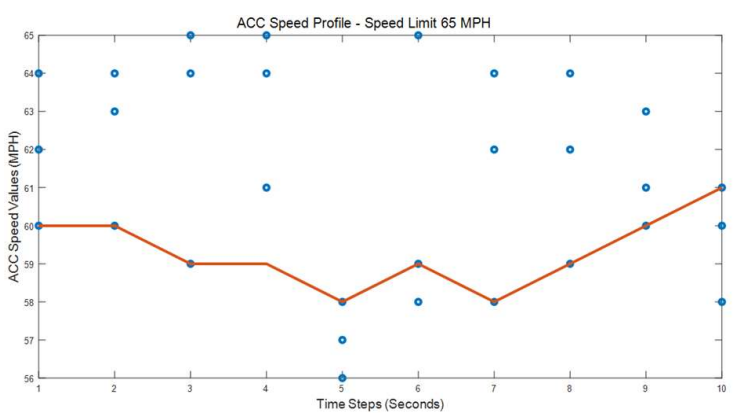

Figure 14. ACCSSP, IAS $=60 \mathrm{MPH}, \mathrm{SL}=65 \mathrm{MPH}$

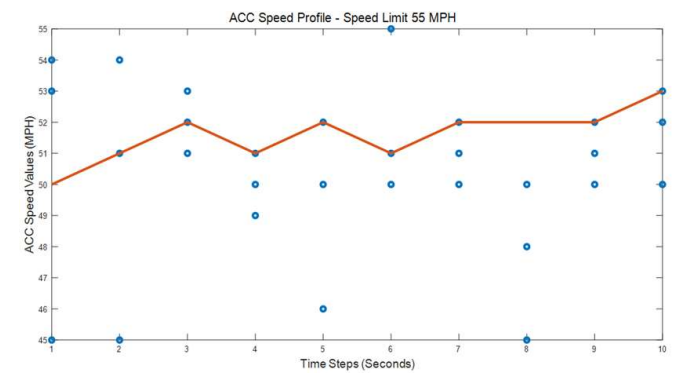

Figure 15. ACCSSP, IAS $=50 \mathrm{MPH}, \mathrm{SL}=55 \mathrm{MPH}$

We adopted a similar procedure for multiple data sets and plotted the predicted ACCSSP's in Figures 12-17. Please find the performance of EOC parameters for the predicted ACCSSP's in Section B: Table 12. 
Author

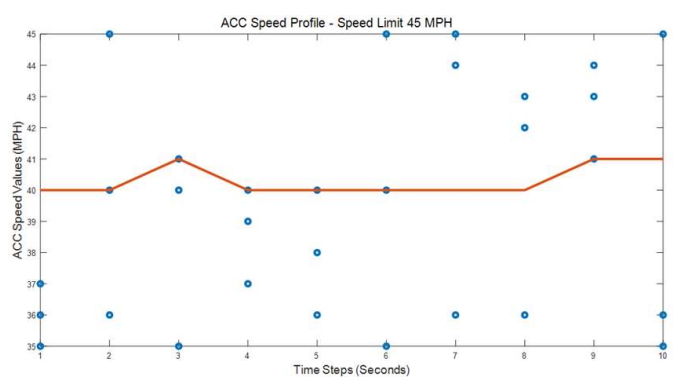

Figure 16. ACCSSP, IAS $=40 \mathrm{MPH}, \mathrm{SL}=45 \mathrm{MPH}$

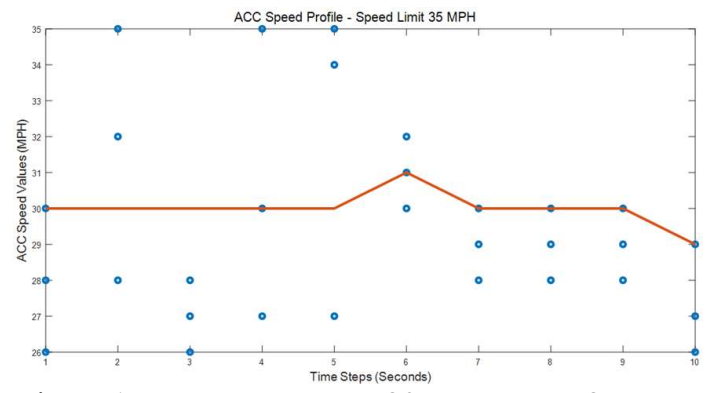

Figure 17. ACCSSP, IAS $=30 \mathrm{MPH}, \mathrm{SL}=35 \mathrm{MPH}$

\section{DISCUSSION}

The plots of predicted EOP's for the three test vehicles Cadillac CT5, XT6, and CT4, are depicted in Figures 5-10. The predictive model is validated by estimating the conformance between actual and predicted data's RMSE, FOD, and SNR (Table 5). The IET RMSE values were < 2.76, whereas IES FOD was $<1.54$ for all the datasets. We recorded the IFCR on a scale of $1 \mathrm{E}-8 \mathrm{~m}^{3} \mathrm{~s}^{-1}$, and the IFCR SNR has an acceptable range of [24.41 30.36]. Also, we can visualise that the predicted curves have a smoother fit to the actual data, and thus efficacy of the DL model to predict EOP is validated.

In this work, we proposed the criteria for augmented EOC and an iterative methodology to predict ACCSSP's, resulting in optimal EOP. Hence, for each future second, the AVS is varied in a definite range [65 75] MPH for the Cadillac XT6, and the corresponding inputs for the future states are fed into the DL model to generate multiple EOPs. We applied EOC criteria to the EOPs, and the top three EVS are estimated as $[69,71,68] \mathrm{MPH}$.

We adopted a similar procedure for ten seconds and predicted ACCSSP for IAS $=70 \mathrm{MPH}, \mathrm{SL}=75 \mathrm{MPH}$, with a minimum of $71 \mathrm{MPH}$ and a maximum of $73 \mathrm{MPH}$ (Figure 13). The predicted and constant ACCSSP profile (70 MPH) with corresponding inputs (section 4.1) were fed into the DL model to obtain two different EOP's vectors (section 4.2) for future time steps (10 s). We applied the EOC criteria for the two EOPs whose values are in Section A:
Table 12 and thus predicted ACCSSP resulted in $934.77 \mathrm{~m}$ of the additional distance traversed and a reduced ED of 373.968 .

We predicted the constant ACCSSP $=70 \mathrm{MPH}$ to consume $379.0951 \mathrm{E}-8 \mathrm{~m}^{3}$ more fuel in $10 \mathrm{~s}$ compared with the predicted ACCSSP. The plots of engine performance parameters are shown in Figure 18, and the area under the curve has higher magnitudes by 1.2 (ETC) and 10.2 (ESC) for the predicted ACCSSP. Please find the smoothness measure for the conformance of the two EOP's in Table 13, and $\mathrm{Adj} / \mathrm{R}$ squares have similar values (conformance $\sim 0$ ), whereas RMSE/SSE have lower values for predicted ACCSSP for most cases. Section B: Table 12 depicts the performance of EOC parameters for all the test cases, and it is easy to see that in most cases, the predicted ACCSSP has reduced ED and IFCR. Hence the proposed approach in this article is novel and better suits enhancing EOC and lowering the trip time.
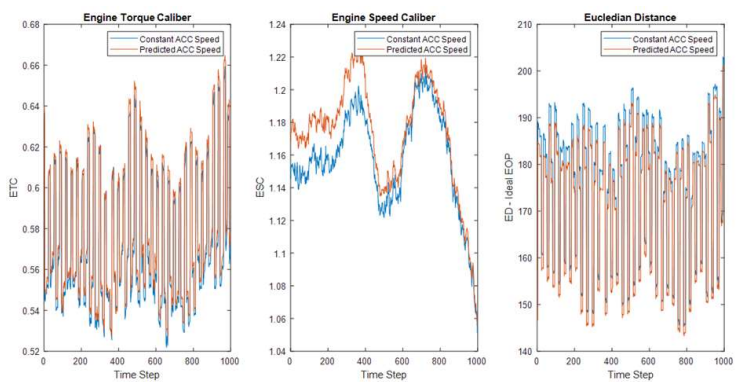

Figure 18. EOC Parameters - [ETC, ESC, ED]

IAS $=70$ MPH, SL $=75$ MPH, 2019 Cadillac XT6

\section{CONCLUSION and FUTURE WORK}

In this manuscript, we developed a novel method to predict the ACCSSP, which optimises engine performance. We considered the vector EOP reflecting engine performance and used NARX DL modelling techniques to predict the EOP by mapping the VLV. We defined EOC criteria, which reflects optimal EOP in real-time. Therefore, a unique ACCSSP for the future time-steps was generated by utilising iterative methods and satisfying the EOC criteria. The computational results obtained were satisfactory, and thus, we observed augmented EOC for the predicted ACCSSP. This novel method could also trigger a new capability in ACC controllers to deviate from the user command of set speed and produce enhanced vehicle performance. We did not include many critical points, including traffic congestion, in the model. Future work would involve developing the model by including all the affecting parameters and performing extensive validation using multiple vehicle lines at various locations and periods.

\section{Additional Information}


Author

Supplementary Materials: There is no supplementary material added for this article.

Author Contributions: The first author (Srikanth Kolachalama) came up with the idea, developed the concept, and performed the complete analysis. The second author (Dr Hafiz Malik) is the principal investigator for this project.

Funding: The project "Predictive model of ACCSSP" was performed under the research collaboration of the University of Michigan and GMC, funded by William J. Clifford (Director) of the Systems Engineering department at GMC.

Data Availability Statement: The data used in this work are proprietary to GMC and cannot be made publicly available. However, the modelling algorithm is available on request.

Acknowledgements: The authors would like to thank Iqbal Surti, Systems Engineer, for his assistance in real-time testing. The technical analysis was performed using the tools provided by GMC (Vehicle Spy and neoVI) and the University of Michigan (MATLAB).

Conflicts of Interest: None. The authors of this manuscript declare that there is no conflict of interest regarding the publication of this article.

\section{Abbreviations:}

ACCSSP: Adaptive cruise control set speed profile (MPH) Area: Area under the curve

AVS: Allowable vehicle speeds

CAN: Controller Area Network

CAT: Cabin air temperature $\left({ }^{\circ} \mathrm{F}\right)$

DL: Deep Learning

DBV: Driver behaviour vector

EAT: External air temperature $\left({ }^{\circ} \mathrm{F}\right)$

ED: Euclidean Distance-Ideal EOP

EOC: Engine Operating Conditions

EOP: Engine Operating Point

ESC: Engine Speed Caliber

EVS: Eligible vehicle speeds

ETC: Engine Torque Caliber

FOD: First Order Derivative

IAS: Initial ACC Speed (MPH)

IES: Instantaneous Engine Speed ( $\mathrm{rad} / \mathrm{s})$

IET: Instantaneous Engine Torque (Nm)

IFCR: Instantaneous Fuel Consumption Rate ( $1 \mathrm{E}-8 m^{3} s^{-1}$ )

ISB: Ideal Steering Behavior

LAT: Lateral acceleration $\left(\mathrm{m} . \mathrm{s}^{-2}\right)$

LOT: Longitudinal acceleration $\left(\mathrm{m} . \mathrm{s}^{-2}\right)$

LSTM: Long Short-Term Memory

GMC: General Motors Corporation

MPH: Miles per Hour

MY: Model Year

NARX: Autoregressive Network with Exogenous Inputs

RMSE: Root Mean Square Error

RRC: Radius of Road Curvature (m)

SL: Speed Limit (MPH)
SNR: Signal to Noise Ratio

SSE: Sum of Squared errors

TP: Tire Pressure $(\mathrm{kPa})$

TPFL: Tire pressure front left $(\mathrm{kPa})$

TPFR: Tire pressure front right $(\mathrm{kPa})$

TPRL: Tire pressure rear left $(\mathrm{kPa})$

TPRR: Tire pressure rear right $(\mathrm{kPa})$

VLV: Vehicle level vectors

YAR: Yaw rate ( $\mathrm{rad} / \mathrm{s})$

\section{Nomenclature:}

\begin{tabular}{|c|l|}
\hline$A_{c}$ & Area of vehicle cross section $\left(\mathrm{m}^{2}\right)$ \\
\hline$C_{d}$ & Aerodynamic drag coefficient. \\
\hline${ }^{\circ} \mathrm{C}$ & Centigrade \\
\hline${ }^{\circ} \mathrm{F}$ & Fahrenheit \\
\hline $\mathrm{g}$ & Gravity \\
\hline $\mathrm{Hz}$ & Hertz \\
\hline $\mathrm{kPa}$ & Kilopascals \\
\hline $\mathrm{Kg}$ & Kilogram \\
\hline $\mathrm{Km}$ & Kilometers \\
\hline$L_{a(k)}$ & Lateral acceleration at time step k $\left(\mathrm{m} . \mathrm{s}^{-2}\right)$ \\
\hline$L_{o(k)}$ & Longitudinal acceleration at time step $\mathrm{k}\left(\mathrm{m} . \mathrm{s}^{-2}\right)$ \\
\hline$M_{c}$ & Mass of the vehicle. $(\mathrm{Kg})$ \\
\hline$M_{L}$ & Mass of the additional load $(\mathrm{Kg})$ \\
\hline $\mathrm{MPH}$ & Miles per hour \\
\hline $\mathrm{m}$ & Meters \\
\hline$m^{2}$ & Meter square $($ Measure of area $)$ \\
\hline$m^{3} s^{-1}$ & Meter cube per second $($ Volume rate flow). \\
\hline $\mathrm{m} . s^{-2}$ & Meters per second square. \\
\hline $\mathrm{ms}$ & Milli seconds \\
\hline $\mathrm{Nm}$ & Newton meter \\
\hline$\mu_{r}$ & Rolling coefficient \\
\hline $\mathrm{PSI}$ & Pound per square inch \\
\hline $\mathrm{rad}$ & Radians \\
\hline $\mathrm{rad} / \mathrm{s}$ & Radians per second \\
\hline$R R C_{k}$ & Radius of road curvature at time step k (m) \\
\hline$\rho$ & Density of air $\left(\mathrm{kg} . \mathrm{m}^{-3}\right)$ \\
\hline $\mathrm{s}$ & Seconds \\
\hline$T_{k}$ & Timestep \\
\hline$d T$ & Incremental time step. $(\sim 10 \mathrm{~ms})$ \\
\hline$\theta_{g(k)}$ & Gradient of the terrain at time step k (rad) \\
\hline$Y_{a(k)}$ & Yaw rate at time step $\mathrm{k}(\mathrm{rad} / \mathrm{s})$ \\
\hline & \\
\hline
\end{tabular}

\section{REFERENCES}

1. Townsend, J.D. and Calantone, R.J., 2014. Evolution and transformation of innovation in the global automotive industry. Journal of product innovation management, 31(1), pp.4-7.

2. Katzenbach, A., 2015. Automotive. In Concurrent engineering in the 21st century (pp. 607-638). Springer, Cham. 
3. Labuhn, P.I. and Chundrlik Jr, W.J., Motors Liquidation Co, 1995. Adaptive cruise control. U.S. Patent 5,454,442.

4. Marsden, G., McDonald, M. and Brackstone, M., 2001. Towards an understanding of adaptive cruise control. Transportation Research Part C: Emerging Technologies, 9(1), pp.33-51.

5. Mahdinia, I., Arvin, R., Khattak, A.J. and Ghiasi, A., 2020. Safety, energy, and emissions impacts of adaptive cruise control and cooperative adaptive cruise control. Transportation Research Record, 2674(6), pp.253-267.

6. Stanton, N.A. and Young, M.S., 2005. Driver behaviour with adaptive cruise control. Ergonomics, 48(10), pp.1294-1313.

7. Hoedemaeker, M. and Brookhuis, K.A., 1998. Behavioural adaptation to driving with an adaptive cruise control (ACC). Transportation Research Part F: Traffic Psychology and Behaviour, 1(2), pp.95-106.

8. Kesting, A., Treiber, M., Schönhof, M., Kranke, F.and Helbing, D., 2007. Jam-avoiding adaptive cruise control (ACC) and its impact on traffic dynamics. In Traffic and Granular Flow'05 (pp. 633-643). Springer, Berlin, Heidelberg.

9. Rudin-Brown, C.M. and Parker, H.A., 2004. Behavioural adaptation to adaptive cruise control (ACC): implications for preventive strategies. Transportation Research Part F: Traffic Psychology and Behaviour, 7(2), pp.59-76.

10. Moon, S. and Yi, K., 2008. Human driving databased design of a vehicle adaptive cruise control algorithm. Vehicle System Dynamics, 46(8), pp.661-690.

11. Rosenfeld, A., Bareket, Z., Goldman, C.V., LeBlanc, D.J. and Tsimhoni, O., 2015. Learning drivers' behavior to improve adaptive cruise control. Journal of Intelligent Transportation Systems, 19(1), pp.18-31.

12. Milanés, V., Shladover, S.E., Spring, J., Nowakowski, C., Kawazoe, H. and Nakamura, M., 2013. Cooperative adaptive cruise control in real traffic situations. IEEE Transactions on intelligent transportation systems, 15(1), pp.296305.

13. Milanés, V. and Shladover, S.E., 2014. Modeling cooperative and autonomous adaptive cruise control dynamic responses using experimental data. Transportation Research Part C: Emerging Technologies, 48, pp.285-300.

14. Kesting, A., Treiber, M., Schönhof, M. and Helbing, D., 2008. Adaptive cruise control design for active congestion avoidance. Transportation Research Part C: Emerging Technologies, 16(6), pp.668-683.
15. Ploeg, J., Serrarens, A.F. and Heijenk, G.J., 2011. Connect \& Drive: design and evaluation of cooperative adaptive cruise control for congestion reduction. Journal of Modern Transportation, 19(3), pp.207-213.

16. Lin, D.Y., Hou, B.J. and Lan, C.C., 2017. A balancing cam mechanism for minimizing the torque fluctuation of engine camshafts. Mechanism and Machine Theory, 108, pp.160175.

17. Lu, C., Dong, J. and Hu, L., 2019. Energyefficient adaptive cruise control for electric connected and autonomous vehicles. IEEE Intelligent Transportation Systems Magazine, 11(3), pp.42-55.

18. Vedam, N., 2015. Terrain-Adaptive Cruise Control: A Human-Like Approach (Doctoral dissertation).

19. Kolmanovsky, I.V. and Filev, D.P., 2010. Terrain and traffic optimized vehicle speed control. IFAC Proceedings Volumes, 43(7), pp.378-383.

20. Gáspár, P. and Németh, B., 2014. Design of adaptive cruise control for road vehicles using topographic and traffic information. IFAC Proceedings Volumes, 47(3), pp.4184-4189.

21. Németh, B. and Gáspár, P., 2011. Road inclinations in the design of LPV-based adaptive cruise controlᄎ. IFAC Proceedings Volumes, 44(1), pp.2202-2207.

22. Németh, B. and Gáspár, P., 2013. Design of vehicle cruise control using road inclinations. International Journal of Vehicle Autonomous Systems, 11(4), pp.313-333.

23. Ma, J., Hu, J., Leslie, E., Zhou, F., Huang, P. and Bared, J., 2019. An eco-drive experiment on rolling terrains for fuel consumption optimization with connected automated vehicles. Transportation Research Part C: Emerging Technologies, 100, pp.125-141.

24. Kolachalama, S. and Lakshmanan, S., 2021. Using Deep Learning to Predict the Engine Operating Point in Real-Time (No. 2021-010186). SAE Technical Paper.

25. Diaconescu, E., 2008. The use of NARX neural networks to predict chaotic time series. Wseas Transactions on computer research, 3(3), pp.182191.

26. Kolachalama, S., Hay, CL., Mushtarin, T., Todd, N., Heitman, J., Hermiz, S., 2018, An Algorithm to Estimate Steering Behavior Using Vehicle Radius Of Curvature, 647068, Research Disclosure, Questel Ireland Ltd.

27. Kolachalama, S., Kuppa, K., Mattam, D. and Shukla, M., 2008, January. Thermal Analysis of Radiator Core in Heavy Duty Automobile. In 
Author

Heat Transfer Summer Conference (Vol. 48487, pp. 123-127).

28. Eathakota, V.P., Kolachalama, S., Krishna, K.M. and Sanan, S., 2008. Optimal posture control for force actuator based articulated suspension vehicle for rough terrain mobility. In Advances In Mobile Robotics (pp. 760-767).

29. Eathakota, V., Singh, A.K., Kolachalama, S. and Krishna, K.M., 2010, September. Determination of optimally stable posture for force actuator based articulated suspension for rough terrain mobility. In FIRA RoboWorld Congress (pp. 154161). Springer, Berlin, Heidelberg.

30. Tanaka, H., Tokushima, T., Higashi, H. and Hamada, S., Mazda Motor Corp, 1987. Means for suppressing engine output torque fluctuations. U.S. Patent 4,699,097.

31. Li, S.E., Guo, Q., Xu, S., Duan, J., Li, S., Li, C. and $\mathrm{Su}, \mathrm{K} ., 2017$. Performance enhanced predictive control for adaptive cruise control system considering road elevation information. IEEE Transactions on Intelligent Vehicles, 2(3), pp.150-160.

32. La Valle, S.M., 2011. Motion planning. IEEE Robotics \& Automation Magazine, 18(2), pp.108118.

33. Li, R., Liu, C. and Luo, F., 2008, September. A design for automotive CAN bus monitoring system. In 2008 IEEE vehicle power and propulsion conference (pp. 1-5). IEEE.

34. Gallardo, F.B., 2018. EXTRACTION AND ANALYSIS OF CAR DRIVING DATA VIA OBDII (Doctoral dissertation, UNIVERSIDAD MIGUEL HERNÁNDEZ DE ELCHE). 
Author

LIST OF TABLES

\begin{tabular}{|c|c|c|c|c|c|c|}
\hline Parameters & \multicolumn{2}{|c|}{ ACC Speed [25 35] MPH } & \multicolumn{3}{c|}{ ACC Speed [35 45] MPH } \\
\hline Inputs & Mean & StdDev & Variation & Mean & StdDev & Variation \\
\hline Absolute time $(\mathrm{s})$ & 2468.020 & 1655.047 & 0.671 & 4584.239 & 2453.828 & 0.535 \\
\hline Odometer $(\mathrm{km})$ & 11721.440 & 41.765 & 0.004 & 11596.730 & 56.886 & 0.005 \\
\hline Speed $(\mathrm{MPH})$ & 30.831 & 2.859 & 0.093 & 40.634 & 2.768 & 0.068 \\
\hline Acceleration $\left(\mathrm{m} / \mathrm{s}^{\wedge} 2\right)$ & 1.090 & 0.652 & 0.598 & 0.808 & 0.449 & 0.556 \\
\hline LOT $\left(\mathrm{m} / \mathrm{s}^{\wedge} 2\right)$ & 0.933 & 0.633 & 0.678 & 0.670 & 0.411 & 0.614 \\
\hline LAT $\left(\mathrm{m} / \mathrm{s}^{\wedge} 2\right)$ & 0.318 & 0.637 & 2.002 & 0.362 & 0.335 & 0.924 \\
\hline YAR $(\mathrm{deg} / \mathrm{sec})$ & 0.098 & 2.633 & 26.944 & 0.179 & 1.056 & 5.914 \\
\hline EAT $\left({ }^{\circ} \mathrm{F}\right)$ & 12.964 & 0.688 & 0.053 & 14.727 & 1.742 & 0.118 \\
\hline $\mathrm{CAT}\left({ }^{\circ} \mathrm{F}\right)$ & 66.141 & 0.348 & 0.005 & 68.895 & 1.069 & 0.016 \\
\hline TPFL $(\mathrm{kPa})$ & 225.908 & 2.915 & 0.013 & 226.990 & 3.243 & 0.014 \\
\hline TPRL $(\mathrm{kPa})$ & 235.773 & 4.640 & 0.020 & 239.900 & 4.259 & 0.018 \\
\hline TPFR $(\mathrm{kPa})$ & 235.115 & 4.834 & 0.021 & 235.575 & 3.706 & 0.016 \\
\hline TPRR $(\mathrm{kPa})$ & 234.132 & 5.742 & 0.025 & 237.544 & 4.270 & 0.018 \\
\hline Outputs & Mean & Deviation & Variation & Mean & Deviation & Variation \\
\hline IET $(\mathrm{Nm})$ & 173.081 & 45.424 & 0.262 & 186.309 & 30.686 & 0.165 \\
\hline IES $(\mathrm{rad} / \mathrm{s})$ & 219.483 & 82.421 & 0.376 & 222.809 & 73.464 & 0.330 \\
\hline IFCR $\left(1 \mathrm{E}-8 \mathrm{~m} \mathrm{~m}^{\wedge} 3 / \mathrm{s}\right)$ & 380.687 & 204.214 & 0.536 & 378.523 & 139.192 & 0.368 \\
\hline
\end{tabular}

Table 1: Data Set 1: 2020 Cadillac CT5 —Arterial Roads

\begin{tabular}{|c|c|c|c|c|c|c|}
\hline Parameters & \multicolumn{2}{|c|}{ ACC Speed [45 55] MPH } & \multicolumn{3}{c|}{ ACC Speed [55 65] MPH } \\
\hline Inputs & Mean & StdDev & Variation & Mean & StdDev & Variation \\
\hline Absolute time $(\mathrm{s})$ & 3701.490 & 1808.730 & 0.489 & 2933.845 & 1442.236 & 0.492 \\
\hline Odometer $(\mathrm{km})$ & 11410.820 & 42.130 & 0.004 & 11894.840 & 36.372 & 0.003 \\
\hline Speed $(\mathrm{MPH})$ & 51.354 & 2.605 & 0.051 & 60.707 & 2.821 & 0.046 \\
\hline Acceleration $\left(\mathrm{m} / \mathrm{s}^{\wedge}\right)$ & 0.500 & 0.210 & 0.420 & 0.415 & 0.208 & 0.501 \\
\hline LOT $\left(\mathrm{m} / \mathrm{s}^{\wedge} 2\right)$ & 0.336 & 0.208 & 0.619 & 0.257 & 0.214 & 0.835 \\
\hline LAT $\left(\mathrm{m} / \mathrm{s}^{\wedge}\right)$ & 0.256 & 0.193 & 0.751 & 0.305 & 0.180 & 0.590 \\
\hline YAR $(\mathrm{deg} / \mathrm{sec})$ & -0.190 & 0.534 & -2.805 & -0.030 & 0.473 & -15.914 \\
\hline EAT $\left({ }^{\circ} \mathrm{F}\right)$ & 12.889 & 0.556 & 0.043 & 15.083 & 0.670 & 0.044 \\
\hline CAT $\left({ }^{\circ} \mathrm{F}\right)$ & 69.726 & 0.688 & 0.010 & 66.000 & 0.000 & 0.000 \\
\hline TPFL $(\mathrm{kPa})$ & 235.424 & 3.508 & 0.015 & 239.108 & 2.371 & 0.010 \\
\hline TPRL $(\mathrm{kPa})$ & 233.685 & 3.947 & 0.017 & 237.436 & 2.193 & 0.009 \\
\hline TPFR $(\mathrm{kPa})$ & 226.567 & 3.062 & 0.014 & 228.252 & 0.972 & 0.004 \\
\hline TPRR $(\mathrm{kPa})$ & 233.767 & 3.764 & 0.016 & 238.294 & 2.279 & 0.010 \\
\hline Outputs & Mean & Deviation & Variation & Mean & Deviation & Variation \\
\hline IET $(\mathrm{Nm})$ & 234.943 & 25.244 & 0.107 & 254.370 & 27.752 & 0.109 \\
\hline IES $(\mathrm{rad} / \mathrm{s})$ & 167.982 & 28.195 & 0.168 & 180.272 & 36.291 & 0.201 \\
\hline IFCR $\left(1 \mathrm{E}-8 \mathrm{~m} \mathrm{~m}^{\wedge} 3 / \mathrm{s}\right)$ & 374.715 & 82.660 & 0.221 & 441.351 & 109.691 & 0.249 \\
\hline
\end{tabular}

Table 2: Data Set 2: 2020 Cadillac CT5-State Ways Roads

\begin{tabular}{|c|c|c|c|c|c|c|}
\hline Parameters & \multicolumn{2}{|c|}{ Cadillac XT6, ACC Speed [65 75] MPH } & \multicolumn{2}{c|}{ Cadillac CT4, ACC Speed [75 85] MPH } \\
\hline Inputs & Mean & StdDev & Variation & Mean & StdDev & Variation \\
\hline Absolute time (s) & 387.430 & 223.687 & 0.577 & 31.709 & 12.962 & 0.409 \\
\hline Odometer (km) & 12723.040 & 7.015 & 0.001 & 30298.330 & 17.042 & 0.001 \\
\hline Speed (MPH) & 70.121 & 1.149 & 0.016 & 77.905 & 1.501 & 0.019 \\
\hline
\end{tabular}


Author

\begin{tabular}{|c|c|c|c|c|c|c|}
\hline Acceleration $\left(\mathrm{m} / \mathrm{s}^{\wedge} 2\right)$ & 0.004 & 0.242 & 67.073 & 0.081 & 0.177 & 2.175 \\
\hline LOT $\left(\mathrm{m} / \mathrm{s}^{\wedge} 2\right)$ & -0.091 & 0.188 & -2.079 & 0.108 & 0.189 & 1.748 \\
\hline LAT $\left(\mathrm{m} / \mathrm{s}^{\wedge} 2\right)$ & 0.132 & 0.339 & 2.572 & -0.149 & 0.307 & -2.057 \\
\hline YAR $(\mathrm{deg} / \mathrm{sec})$ & 0.230 & 0.851 & 3.698 & -0.256 & 0.694 & -2.710 \\
\hline EAT $\left({ }^{\circ} \mathrm{F}\right)$ & 39.225 & 0.296 & 0.008 & 85.039 & 0.998 & 0.012 \\
\hline CAT $\left({ }^{\circ} \mathrm{F}\right)$ & 68.785 & 0.301 & 0.004 & 66.502 & 0.862 & 0.013 \\
\hline Pitch angle $(\mathrm{deg})$ & -0.262 & 0.742 & -2.836 & -0.003 & 0.002 & -0.771 \\
\hline TPFL $(\mathrm{kPa})$ & 241.238 & 2.428 & 0.010 & 227.807 & 0.289 & 0.001 \\
\hline TPRL $(\mathrm{kPa})$ & 235.890 & 0.655 & 0.003 & 249.502 & 0.290 & 0.001 \\
\hline TPFR $(\mathrm{kPa})$ & 243.691 & 1.069 & 0.004 & 228.316 & 0.409 & 0.002 \\
\hline TPRR $(\mathrm{kPa})$ & 235.224 & 1.582 & 0.007 & 249.503 & 0.287 & 0.001 \\
\hline Outputs & Mean & Deviation & Variation & Mean & Deviation & Variation \\
\hline IET $(\mathrm{Nm})$ & 146.803 & 63.428 & 0.432 & 142.117 & 33.698 & 0.237 \\
\hline IES $(\mathrm{rad} / \mathrm{s})$ & 183.081 & 7.105 & 0.039 & 205.343 & 17.341 & 0.084 \\
\hline IFCR $\left(1 \mathrm{E}-8 \mathrm{~m} \mathrm{~m}^{\wedge} 3 / \mathrm{s}\right)$ & 387.430 & 223.687 & 0.577 & 31.709 & 12.962 & 0.409 \\
\hline
\end{tabular}

Table 3: Data Set 3: 2019 Cadillac XT6, 2021 Cadillac CT4-Freeways Roads

\begin{tabular}{|c|c|c|c|c|c|}
\hline \multicolumn{6}{|c|}{ NARX_-Deep Learning Model } \\
\hline \multicolumn{2}{|c|}{ Properties } & \multicolumn{4}{|c|}{ Dataset-Training and Testing } \\
\hline Property & Value & Vehicle & Training & Test Size & $\begin{array}{c}\text { ACCSSP } \\
\text { (MPH) }\end{array}$ \\
\hline Training function & $\begin{array}{c}\text { Levenberg-Marquardt } \\
\text { backpropagation }\end{array}$ & 2020 Cadillac CT5 & $1-14000$ & $14001-15000$ & 30 \\
\hline Input delays & $1: 2$ & 2020 Cadillac CT5 & $1-24000$ & $24001-25000$ & 40 \\
\hline Feedback delays & $1: 2$ & 2020 Cadillac CT5 & $1-34000$ & $34001-35000$ & 50 \\
\hline Hidden layer size & 10 & 2020 Cadillac CT5 & $1-44000$ & $44001-45000$ & 60 \\
\hline Network & Open & 2019 Cadillac XT6 & $1-40000$ & $40001-41000$ & 70 \\
\hline Performance & MSE & 2021 Cadillac CT4 & $1-25000$ & $25001-26000$ & 80 \\
\hline
\end{tabular}

Table 4: Prediction of EOP-NARX DL Model

\begin{tabular}{|c|c|c|c|c|c|c|c|c|c|}
\hline EOP & \multicolumn{3}{|c|}{ IET } & \multicolumn{3}{c|}{ IES } & \multicolumn{3}{c|}{ IFCR } \\
\hline Metric & RMSE & FOD & SNR & RMSE & FOD & SNR & RMSE & FOD & SNR \\
\hline $30 \mathrm{MPH}$ & 2.761 & 1.911 & 35.003 & 2.367 & 1.541 & 35.417 & 12.911 & 8.717 & 25.499 \\
\hline $40 \mathrm{MPH}$ & 0.750 & 0.418 & 45.362 & 0.845 & 0.484 & 37.442 & 14.122 & 9.477 & 24.418 \\
\hline $50 \mathrm{MPH}$ & 1.263 & 0.811 & 45.566 & 1.400 & 0.932 & 43.413 & 18.966 & 13.289 & 25.495 \\
\hline $60 \mathrm{MPH}$ & 0.590 & 0.417 & 51.103 & 0.521 & 0.348 & 51.414 & 21.740 & 15.241 & 25.582 \\
\hline $70 \mathrm{MPH}$ & 0.322 & 0.186 & 53.762 & 0.228 & 0.169 & 58.007 & 8.335 & 5.877 & 30.369 \\
\hline $80 \mathrm{MPH}$ & 0.576 & 0.618 & 46.651 & 0.064 & 0.027 & 70.160 & 9.917 & 6.879 & 27.586 \\
\hline
\end{tabular}

Table 5: NARX Model Performance-ACCSSP [30 80] MPH

\begin{tabular}{|c|c|c|c|c|c|c|c|c|c|}
\hline \multirow{2}{*}{\multicolumn{4}{|c|}{$\begin{array}{c}\text { Section A } \\
\text { Ideal EOP }\end{array}$}} & \multicolumn{6}{|c|}{ Section B } \\
\hline & & & & \multicolumn{2}{|c|}{ Generic } & \multicolumn{2}{|c|}{ Engine specific } & \multicolumn{2}{|c|}{$\begin{array}{c}\text { Smoothness Measure } \\
\text { - spline fit }\end{array}$} \\
\hline Vehicle & $\begin{array}{l}\text { IET } \\
(\mathrm{Nm})\end{array}$ & $\begin{array}{c}\text { IES } \\
(\mathrm{rad} / \mathrm{s})\end{array}$ & $\begin{array}{l}\text { IFCR } \\
(1 \mathrm{E}- \\
\left.8 m^{3} s^{-1}\right)\end{array}$ & Parameter & Condition & Parameter & Condition & Parameter & Condition \\
\hline Cadillac CT5 & 250 & 140 & 180 & IET & Higher & ED & Lower & $\mathrm{Adj} / \mathrm{R}$ & Higher \\
\hline Cadillac XT6 & 280 & 145 & 220 & IES & Higher & ESC & Higher & RMSE & Lower \\
\hline Cadillac CT4 & 240 & 140 & 200 & IFCR & Lower & ETC & Higher & $\mathrm{SSE}$ & Lower \\
\hline
\end{tabular}


Table 6: EOC Criteria - EOP

\begin{tabular}{|c|c|c|}
\hline$R R C_{k+1}, \theta_{g(k+1)}$ & $2 R R C_{k+1}=\frac{S_{k+1}^{2}}{L_{a(k+1)}}+\frac{S_{k+1}}{Y_{a(k+1)}}, \min \left[a b s\left(Y_{a(k+1)} \cdot S_{k+1}-L_{a(k+1)}\right)\right]$ & $\rho=1.225 \mathrm{~kg} . \mathrm{m}^{-3}$ \\
\hline$T_{k+1}=T_{k}+d T$ & $L_{o(k+1)}=g \mu_{r}+g \sin \left(\theta_{g(k+1)}\right)+\frac{\rho C_{d} \cdot A_{c}}{2 .\left(M_{c}+M_{L}\right)} \cdot S_{k+1}^{2}$ & $S_{k+1}=[S L-10, S L]$ \\
\hline $\begin{array}{l}O_{k+1} \\
=O_{k}+S_{k} . d T\end{array}$ & 2020 Cadillac CT5: $M_{c}=1769.69 \mathrm{~kg}, M_{L}=76.8 \mathrm{~kg}, C_{d}=0.31, \mathrm{~A}=1.71 m^{2}$ & $C A T_{k+1}=C A T_{k}$ \\
\hline$E A T_{k+1}=E A T_{k}$ & 2019 Cadillac XT6: $M_{c}=2050.278 \mathrm{~kg}, M_{L}=76.8 \mathrm{~kg}, C_{d}=0.35, \mathrm{~A}=1.88 m^{2}$ & $\mathrm{~g}=9.81 \mathrm{~m} . s^{-2}$ \\
\hline$T P_{k+1}=T P_{k}$ & 2021 Cadillac CT4: $M_{c}=1626.94 \mathrm{~kg}, M_{L}=76.8 \mathrm{~kg}, C_{d}=0.30, \mathrm{~A}=1.70 m^{2}$ & $\mu_{r}=0.013$ \\
\hline
\end{tabular}

Table 7: Equation set - Prediction of future input states.

\begin{tabular}{|c|c|c|c|c|c|c|}
\hline Time Step & $\begin{array}{c}\text { Odometer } \\
(\mathbf{M i l e s})\end{array}$ & $\begin{array}{c}\text { Speed } \\
(\mathbf{M P H})\end{array}$ & $\begin{array}{c}\text { RRC } \\
(\mathbf{m})\end{array}$ & $\begin{array}{c}\text { YAR } \\
(\mathbf{d e g} / \mathbf{s})\end{array}$ & $\begin{array}{c}\text { LAT } \\
\left({\mathrm{m} . \mathrm{s}^{-2}}^{\mathbf{2}}\right)\end{array}$ & $\begin{array}{c}\text { LOT } \\
\left(\mathrm{m} . \mathrm{s}^{-2}\right)\end{array}$ \\
\hline$T_{0}$ & 15000 & 70 & 8304.140 & 0.216 & 0.117 & 0.437 \\
\hline$d T_{10}$ & 15000.001 & 70 & 8304.140 & 0.216 & 0.117 & 0.375 \\
\hline$d T_{20}$ & 15000.003 & 70 & 8304.140 & 0.216 & 0.117 & 0.312 \\
\hline$d T_{30}$ & 15000.005 & 70 & 9342.157 & 0.192 & 0.104 & -0.125 \\
\hline$d T_{40}$ & 15000.007 & 70 & 24912.42 & 0.072 & 0.039 & -0.187 \\
\hline$d T_{50}$ & 15000.009 & 70 & 74737.261 & 0.024 & 0.013 & -0.062 \\
\hline$d T_{60}$ & 15000.011 & 70 & 74737.261 & 0.024 & 0.013 & 0.25 \\
\hline$d T_{70}$ & 15000.013 & 70 & 37368.630 & 0.048 & 0.026 & 0.25 \\
\hline$d T_{80}$ & 15000.015 & 70 & 24912.420 & 0.072 & 0.039 & 0.187 \\
\hline$d T_{90}$ & 15000.017 & 70 & 24912.420 & 0.072 & 0.039 & 0.187 \\
\hline$T_{1}$ & 15000.019 & 70 & 9342.157 & 0.192 & 0.104 & 0.312 \\
\hline
\end{tabular}

Table 8: Predicted Inputs—DL Model, 2019 Cadillac XT6 (100 Time steps = 1 second $)$

\begin{tabular}{|c|c|c|c|c|c|c|c|c|c|c|c|c|}
\hline EOP & Speed & 65 & 66 & 67 & 68 & 69 & 70 & 71 & 72 & 73 & 74 & 75 \\
\hline \multirow{5}{*}{ IET } & Area & $1.6 \mathrm{E}+04$ & $3.1 \mathrm{E}+04$ & $4.7 \mathrm{E}+04$ & $6.2 \mathrm{E}+04$ & $7.8 \mathrm{E}+04$ & $9.4 \mathrm{E}+04$ & $1.1 \mathrm{E}+05$ & $1.2 \mathrm{E}+05$ & $1.4 \mathrm{E}+05$ & $1.6 \mathrm{E}+05$ & $1.7 \mathrm{E}+05$ \\
\hline & $\mathrm{R}$ & 0.76 & 0.83 & \begin{tabular}{|l|}
0.77 \\
\end{tabular} & \begin{tabular}{|l|}
0.74 \\
\end{tabular} & \begin{tabular}{|l|}
0.77 \\
\end{tabular} & \begin{tabular}{|l|}
0.77 \\
\end{tabular} & \begin{tabular}{|l|}
0.75 \\
\end{tabular} & \begin{tabular}{|l|}
0.77 \\
\end{tabular} & \begin{tabular}{|l|}
0.75 \\
\end{tabular} & \begin{tabular}{|l|}
0.78 \\
\end{tabular} & \begin{tabular}{|l|}
0.76 \\
\end{tabular} \\
\hline & Adj R & 0.4 & 0.57 & 0.43 & 0.36 & 0.44 & 0.43 & 0.39 & 0.44 & 0.37 & 0.44 & 0.4 \\
\hline & $\mathrm{SSE}$ & 6.26 & 4.47 & 5.94 & 6.69 & 5.82 & 5.94 & 6.34 & 5.76 & 6.49 & 5.72 & 6.16 \\
\hline & RMS & 0.4 & \begin{tabular}{|l|}
0.33 \\
\end{tabular} & \begin{tabular}{|l|}
0.39 \\
\end{tabular} & \begin{tabular}{|l|}
0.41 \\
\end{tabular} & \begin{tabular}{|l|}
0.38 \\
\end{tabular} & \begin{tabular}{|l|}
0.38 \\
\end{tabular} & \begin{tabular}{|l|}
0.4 \\
\end{tabular} & \begin{tabular}{|l|}
0.38 \\
\end{tabular} & \begin{tabular}{|l|}
0.4 \\
\end{tabular} & \begin{tabular}{|l|}
0.38 \\
\end{tabular} & 0.39 \\
\hline \multirow{5}{*}{ IES } & Area & $1.8 \mathrm{E}+04$ & $3.5 \mathrm{E}+04$ & $5.3 \mathrm{E}+04$ & $7.1 \mathrm{E}+04$ & $8.9 \mathrm{E}+04$ & $1.1 \mathrm{E}+05$ & $1.2 \mathrm{E}+05$ & $1.4 \mathrm{E}+05$ & $1.6 \mathrm{E}+05$ & $1.8 \mathrm{E}+05$ & $2.0 \mathrm{E}+05$ \\
\hline & $\mathrm{R}$ & 1 & 1 & \begin{tabular}{|l|}
1 \\
\end{tabular} & \begin{tabular}{|l|}
1 \\
\end{tabular} & \begin{tabular}{|l|}
1 \\
\end{tabular} & \begin{tabular}{|l|}
1 \\
\end{tabular} & \begin{tabular}{|l|}
1 \\
\end{tabular} & \begin{tabular}{|l|}
1 \\
\end{tabular} & $\begin{array}{l}1 \\
\end{array}$ & 1 & 1 \\
\hline & Adj R & 0.99 & 0.99 & 0.99 & 0.99 & 0.99 & 0.99 & 0.99 & 0.99 & 1 & 0.99 & 0.99 \\
\hline & SSE & 0.003 & 0.002 & 0.003 & 0.003 & 0.003 & 0.003 & 0.002 & 0.001 & 0.001 & 0.001 & 0.001 \\
\hline & RMS & 0.009 & 0.007 & \begin{tabular}{|l|}
0.008 \\
\end{tabular} & 0.008 & \begin{tabular}{|l|}
0.009 \\
\end{tabular} & 0.008 & \begin{tabular}{|l|}
0.007 \\
\end{tabular} & 0.006 & 0.005 & 0.006 & 0.006 \\
\hline \multirow{5}{*}{ IFCR } & Area & $2.8 \mathrm{E}+04$ & $5.6 \mathrm{E}+04$ & $8.4 \mathrm{E}+04$ & $1.1 \mathrm{E}+05$ & $1.4 \mathrm{E}+05$ & $1.7 \mathrm{E}+05$ & $1.9 \mathrm{E}+05$ & $2.2 \mathrm{E}+05$ & $2.5 \mathrm{E}+05$ & $2.7 \mathrm{E}+05$ & $3.0 \mathrm{E}+05$ \\
\hline & $\mathrm{R}$ & \begin{tabular}{|l|}
0.78 \\
\end{tabular} & 0.78 & \begin{tabular}{|l|}
0.72 \\
\end{tabular} & 0.74 & $\begin{array}{l}0.8 \\
\end{array}$ & \begin{tabular}{|l|}
0.75 \\
\end{tabular} & \begin{tabular}{|l|}
0.81 \\
\end{tabular} & \begin{tabular}{|l|}
0.74 \\
\end{tabular} & \begin{tabular}{|l|}
0.76 \\
\end{tabular} & \begin{tabular}{|l|}
0.68 \\
\end{tabular} & \begin{tabular}{|l|}
0.67 \\
\end{tabular} \\
\hline & Adj R & 0.46 & 0.45 & 0.31 & 0.35 & 0.5 & 0.37 & 0.53 & 0.36 & 0.4 & 0.22 & 0.17 \\
\hline & SSE & 4913.31 & 4737.99 & 5613.29 & 4967.08 & 3726.95 & 4633.05 & 3429.65 & 4679.59 & 4418.54 & 5766.31 & 6140.52 \\
\hline & RMS & 11.19 & 10.99 & \begin{tabular}{|l|}
11.97 \\
\end{tabular} & 11.26 & \begin{tabular}{|l|}
9.75 \\
\end{tabular} & \begin{tabular}{|l|}
10.85 \\
\end{tabular} & \begin{tabular}{|l|}
9.35 \\
\end{tabular} & \begin{tabular}{|l|}
10.92 \\
\end{tabular} & \begin{tabular}{|l|}
10.62 \\
\end{tabular} & \begin{tabular}{|l|}
12.13 \\
\end{tabular} & \begin{tabular}{|l|}
12.52 \\
\end{tabular} \\
\hline \multirow{5}{*}{ ETC } & Area & $5.4 \mathrm{E}+01$ & $1.1 \mathrm{E}+02$ & $1.6 \mathrm{E}+02$ & $2.2 \mathrm{E}+02$ & $2.8 \mathrm{E}+02$ & $3.3 \mathrm{E}+02$ & $3.9 \mathrm{E}+02$ & $4.5 \mathrm{E}+02$ & $5.0 \mathrm{E}+02$ & $5.6 \mathrm{E}+02$ & $6.2 \mathrm{E}+02$ \\
\hline & $\mathrm{R}$ & \begin{tabular}{|l|}
0.788 \\
\end{tabular} & \begin{tabular}{|l|}
0.781 \\
\end{tabular} & \begin{tabular}{|l|}
0.724 \\
\end{tabular} & \begin{tabular}{|l|}
0.739 \\
\end{tabular} & \begin{tabular}{|l|}
0.802 \\
\end{tabular} & \begin{tabular}{|l|}
0.751 \\
\end{tabular} & \begin{tabular}{|l|}
0.814 \\
\end{tabular} & \begin{tabular}{|l|}
0.745 \\
\end{tabular} & \begin{tabular}{|l|}
0.759 \\
\end{tabular} & \begin{tabular}{|l|}
0.689 \\
\end{tabular} & \begin{tabular}{|l|}
0.671 \\
\end{tabular} \\
\hline & Adj R & 0.469 & 0.452 & 0.309 & 0.348 & 0.504 & 0.377 & 0.535 & 0.362 & 0.398 & 0.222 & 0.176 \\
\hline & $\mathrm{SSE}$ & 0.02 & 0.02 & 0.025 & 0.023 & 0.017 & 0.022 & 0.016 & 0.023 & 0.022 & 0.03 & 0.033 \\
\hline & RMS & 0.022 & 0.023 & 0.025 & 0.024 & 0.021 & 0.023 & 0.02 & 0.024 & 0.024 & 0.028 & 0.029 \\
\hline
\end{tabular}


Author

\begin{tabular}{|c|c|c|c|c|c|c|c|c|c|c|c|c|}
\hline \multirow{5}{*}{ ESC } & Area & $1.1 \mathrm{E}+02$ & $2.2 \mathrm{E}+02$ & $3.3 \mathrm{E}+02$ & $4.5 \mathrm{E}+02$ & $5.6 \mathrm{E}+02$ & $6.7 \mathrm{E}+02$ & $7.8 \mathrm{E}+02$ & $9.0 \mathrm{E}+02$ & $1.0 \mathrm{E}+03$ & $1.1 \mathrm{E}+03$ & $1.2 \mathrm{E}+03$ \\
\cline { 2 - 14 } & R & 0.822 & 0.869 & 0.824 & 0.801 & 0.826 & 0.817 & 0.799 & 0.812 & 0.783 & 0.807 & 0.792 \\
\cline { 2 - 14 } & Adj R & 0.554 & 0.672 & 0.56 & 0.503 & 0.565 & 0.542 & 0.497 & 0.529 & 0.457 & 0.517 & 0.479 \\
\cline { 2 - 14 } & SSE & 0 & 0 & 0 & 0 & 0 & 0 & 0 & 0 & 0 & 0 & 0 \\
\cline { 2 - 14 } & RMS & 0.003 & 0.002 & 0.003 & 0.003 & 0.003 & 0.003 & 0.003 & 0.003 & 0.003 & 0.003 & 0.003 \\
\hline \multirow{5}{*}{ ED } & Area & $1.9 \mathrm{E}+04$ & $3.7 \mathrm{E}+04$ & $5.5 \mathrm{E}+04$ & $7.2 \mathrm{E}+04$ & $9.0 \mathrm{E}+04$ & $1.1 \mathrm{E}+05$ & $1.2 \mathrm{E}+05$ & $1.4 \mathrm{E}+05$ & $1.6 \mathrm{E}+05$ & $1.7 \mathrm{E}+05$ & $1.9 \mathrm{E}+05$ \\
\cline { 2 - 13 } & R & 0.787 & 0.783 & 0.725 & 0.743 & 0.802 & 0.751 & 0.815 & 0.747 & 0.761 & 0.689 & 0.671 \\
\cline { 2 - 13 } & Adj R & 0.467 & 0.457 & 0.311 & 0.358 & 0.504 & 0.378 & 0.538 & 0.368 & 0.402 & 0.222 & 0.176 \\
\cline { 2 - 12 } & SSE & 4896.87 & 4721.42 & 5595.32 & 4950.75 & 3716.68 & 4620.39 & 3421.22 & 4665.06 & 4404.92 & 5749.95 & 6123.26 \\
\cline { 2 - 13 } & RMS & 11.18 & 10.978 & 11.951 & 11.241 & 9.74 & 10.86 & 9.345 & 10.912 & 10.604 & 12.115 & 12.502 \\
\hline
\end{tabular}

Table 9: EOC Criteria-Iteration of ACC Speeds (100-time steps)

\begin{tabular}{|c|c|c|c|c|c|c|c|c|c|c|c|c|c|c|}
\hline Area & $\mathbf{R}$ & Adj & SSE & RMS & Area & $\mathbf{R}$ & $\overline{\text { Adj }}$ & SSE & RMS & Area & $\mathbf{R}$ & Adj & SSE & RMS \\
\hline \multicolumn{5}{|c|}{ IET } & \multicolumn{5}{|c|}{ IES } & \multicolumn{5}{|c|}{ IFCR } \\
\hline 75 & 69 & 69 & 70 & 70 & 75 & 68 & 68 & 75 & 75 & 65 & 66 & 66 & 75 & 75 \\
\hline 74 & 70 & 70 & 69 & 69 & 74 & 71 & 71 & 71 & 71 & 66 & 69 & 69 & 66 & 66 \\
\hline 73 & 65 & 65 & 71 & 71 & 73 & 70 & 70 & 68 & 68 & 67 & 75 & 75 & 69 & 69 \\
\hline 72 & 68 & 68 & 72 & 72 & 72 & 69 & 69 & 70 & 70 & 68 & 65 & 65 & 65 & 65 \\
\hline 71 & 71 & 71 & 68 & 68 & 71 & 67 & 67 & 72 & 72 & 69 & 70 & 70 & 70 & 70 \\
\hline 70 & 73 & 73 & 73 & 73 & 70 & 72 & 72 & 74 & 74 & 70 & 67 & 67 & 72 & 72 \\
\hline \multicolumn{5}{|c|}{ ETC } & \multicolumn{5}{|c|}{ ESC } & \multicolumn{5}{|c|}{ ED } \\
\hline 75 & 66 & 66 & 66 & 66 & 75 & 69 & 69 & 70 & 70 & 65 & 66 & 66 & 75 & 75 \\
\hline 74 & 69 & 69 & 65 & 65 & 74 & 70 & 70 & 69 & 69 & 66 & 69 & 69 & 66 & 66 \\
\hline 73 & 75 & 75 & 69 & 69 & 73 & 68 & 68 & 71 & 71 & 67 & 75 & 75 & 69 & 69 \\
\hline 72 & 65 & 65 & 75 & 75 & 72 & 65 & 65 & 72 & 72 & 68 & 65 & 65 & 70 & 70 \\
\hline 71 & 70 & 70 & 70 & 70 & 71 & 71 & 71 & 73 & 73 & 69 & 70 & 70 & 65 & 65 \\
\hline 70 & 67 & 67 & 67 & 67 & 70 & 66 & 66 & 68 & 68 & 70 & 67 & 67 & 72 & 72 \\
\hline
\end{tabular}

Table 10: Eligible ACC Speeds-EOC Criteria (100-time steps = 1 second)

\begin{tabular}{|c|c|c|c|c|c|c|c|c|c|}
\hline$T_{1}$ & $T_{2}$ & $T_{3}$ & $T_{4}$ & $T_{5}$ & $T_{6}$ & $T_{7}$ & $T_{8}$ & $T_{9}$ & $T_{10}$ \\
\hline 69 & 68 & 66 & 75 & 74 & 67 & 67 & 75 & 67 & 75 \\
\hline 71 & 70 & 65 & 68 & 72 & 71 & 72 & 66 & 75 & 71 \\
\hline 68 & 71 & 67 & 65 & 65 & 74 & 73 & 68 & 73 & 65 \\
\hline
\end{tabular}

Table 11: ACC Speeds-10 seconds, $\mathrm{SL}=75 \mathrm{MPH}$

\begin{tabular}{|c|c|c|c|c|c|c|c|c|c|c|}
\hline \multicolumn{4}{|c|}{ Section: A } & \multicolumn{7}{|c|}{ Section: $B$} \\
\hline Data & \multicolumn{3}{|c|}{$\mathrm{IAS}=70 \mathrm{MPH}, \mathrm{SL}=75 \mathrm{MPH}$} & \multicolumn{2}{|c|}{$\begin{array}{c}\text { Speed } \\
(\mathrm{MPH}) \\
\end{array}$} & \multicolumn{5}{|c|}{ Test Cases } \\
\hline \multirow[b]{2}{*}{ Metric } & \multirow{2}{*}{$\begin{array}{l}\text { ACCSSP } \\
(70 \mathrm{MPH})\end{array}$} & \multirow{2}{*}{$\begin{array}{c}\text { ACCSSP } \\
\text { (Predicted) }\end{array}$} & \multirow[b]{2}{*}{ Conformance } & SL & IAS & Distance & ED & IFCR & ETC & ESC \\
\hline & & & & 35 & 30 & 0.22 & -17.33 & -21.19 & 0.25 & -0.26 \\
\hline Distance & 69930.00 & 72028.00 & 934.77 & 45 & 40 & 133.44 & -64.11 & -52.113 & -0.27 & 0.50 \\
\hline ED & 174570.83 & 174196.86 & -373.96 & 55 & 50 & 712.22 & -366.13 & -323.27 & 0.51 & 1.20 \\
\hline ETC & 572.12 & 573.34 & 1.22 & 65 & 60 & -312.11 & -510.75 & -540.58 & 0.87 & 0.22 \\
\hline ESC & 1154.63 & 1164.83 & 10.20 & 75 & 70 & 934.77 & -373.96 & -379.09 & 1.22 & 10.20 \\
\hline IFCR & 274182.80 & 273803.70 & -379.09 & 85 & 80 & 801.108 & -1035.28 & -1029.6 & 2.813 & -2.022 \\
\hline
\end{tabular}

Table 12: EOC Criteria: Engine parameters (Predicted - Constant) ACCSSP 
Author

\begin{tabular}{|c|c|c|c|c|c|c|c|c|c|c|c|c|c|}
\hline \multicolumn{2}{|c|}{ EOP } & \multicolumn{4}{|c|}{ IET } & \multicolumn{4}{c|}{ IES } & \multicolumn{4}{c|}{ IFCR } \\
\hline SL & IAS & R & Adj R & SSE & RMS & R & $\begin{array}{c}\text { Adj } \\
\text { R }\end{array}$ & SSE & RMS & R & $\begin{array}{c}\text { Adj } \\
\text { R }\end{array}$ & SSE & RMS \\
\hline 35 & 30 & 0.0 & 0.0 & -9.415 & -0.007 & 0.0 & 0.000 & 0.564 & 0.000 & 0.000 & 0.0 & -103.786 & -0.023 \\
\hline 45 & 40 & 0.0 & 0.0 & 0.326 & 0.001 & 0.0 & 0.000 & 2.582 & 0.013 & 0.000 & 0.0 & -23.251 & -0.005 \\
\hline 55 & 50 & 0.0 & 0.0 & 3.069 & 0.007 & 0.0 & 0.001 & -38.090 & -0.033 & 0.000 & 0.0 & -570.595 & -0.083 \\
\hline 65 & 60 & 0.0 & 0.0 & 1.307 & 0.005 & 0.0 & 0.000 & 0.431 & 0.002 & 0.000 & 0.0 & 33.212 & 0.004 \\
\hline 75 & 70 & 0.0 & 0.0 & 0.368 & 0.004 & 0.064 & 0.160 & -2.607 & -0.024 & 0.000 & 0.0 & 136.612 & 0.044 \\
\hline 85 & 80 & 0.0 & 0.0 & -0.312 & -0.001 & -0.002 & -0.005 & 0.142 & 0.007 & 0.001 & 0.002 & -243.889 & -0.068 \\
\hline
\end{tabular}

Table 13: EOC Criteria: Smoothness Performance - (Predicted - Constant) ACCSSP 